\title{
Technology for Granulating Coke Breeze by Centrifugal Rolling Type Pelletizer and Effect of Granulated Coke Breeze on Sintering Operation
}

\author{
Yohzoh HOSOTANI, Norimitsu KONNO, Juzo SHIBATA, ${ }^{1)}$ Tadasi SATO ${ }^{2)}$ and Haruhisa SUZUKI ${ }^{2)}$ \\ Process Technology Research Laboratories, Nippon Steel Corporation, Shintomi, Futtsu, Chiba-ken, 293 Japan. E-mail: \\ y-hosotani@lab.re.nsc.co.jp \\ 1) Nagoya R \& D Laboratory, Nippon Steel Corporation, Tokaimachi, Tokai, Aichi-ken, 476 Japan. \\ 2) Nagoya Works, Nippon Steel Corporation, Tokaimachi, Tokai, Aichi-ken, 476 Japan.
}

(Received on February 23, 1995; accepted in final form on May 26, 1995)

Coke breeze was granulated by a centrifugal rolling type pelletizer which was operated at a Froude number $(F r)$ that is more than $10^{2}$ times that for the conventional drum mixer. The effects of the coke breeze granulated by this new technology on the sintering operation, the granulation of raw mix for sintering, and the quality of sinter were quantitatively studied through sintering pot test and plant test at Nagoya No. 2 Sintering Plant. As a result, the following findings were obtained:

(1) In the coke breeze granulation test, the centrifugal rolling type pelletizer could not only granulate fine coke breeze but also cause ultra-fine coke particles to penetrate into coarser particles, while preventing the granulated particles from becoming excessively coarse.

(2) In the sintering pot test and sintering plant test, it was clarified that granulated coke breeze became the nuclei of quasi-particles of the raw mix for sintering and then promoted the granulation of other raw materials in the iron ore sintering process.

(3) It was confirmed that this new technology could decrease $\mathrm{NO}_{x}$ emissions by reducing the ratio of fine particles in coke breeze. $\mathrm{NO}_{x}$ emissions could be further reduced by the addition of quick lime. It was also clarified that the reducibility of sinter was improved.

KEY WORDS: agglomeration; granulation; iron ore sinter; coke breeze; sintering process.

\section{Introduction}

Much work has been reported on the important effect of particle size distribution in the coke breeze used as a heat source for sintering on the sinterability of iron ore. The combustion of coke breeze is an important factor which has an effect not only on productivity, product yield and sinter quality but also on nitrogen oxide $\left(\mathrm{NO}_{x}\right)$ emissions.

It was reported that the optimum coke particle sizes for combustion efficiency and productivity are from 0.25 to $3 \mathrm{~mm}$ which are neither so fine nor so coarse. ${ }^{1)}$ In commercial operation, various measures were taken to obtain such particle sizes, including the closed type coke crushing and screening plant and the prevention of excessive crushing. However, the improvement of crushing method only was not sufficient, because the ratio of particles larger than $3 \mathrm{~mm}$ increased if the ratio of particles smaller than $0.25 \mathrm{~mm}$ was decreased, but the ratio of particles under $0.25 \mathrm{~mm}$ increased if the ratio of particles above $3 \mathrm{~mm}$ was reduced.

In the rolling type granulation by drum mixer or disc pelletizer which is conventionally used at the sintering process, fine particles adhere to the nucleus particles in a snowballing manner and the particle size distribution in the granulated coke becomes wider, resulting in an increased ratio of coarse particles. A method in which the centrifugal force is increased by increasing the Froude number and the coke breeze is granulated by the friction with the cylinder and other parts of the pelletizer was reported. ${ }^{2,3)}$ This method is considered to be effective for the prevention of particles from becoming excessively coarse.

Against this background, the importance of particle size of coke breeze was studied through mathematical model analysis. Then, sintering pot and sintering plant tests were conducted by using a centrifugal rolling type pelletizer, which is operated at a Froude number that is more than $10^{2}$ times those for drum mixer and disc pelletizer, to coke breeze granulation.

\section{Past Studies}

Much work has been done on the evaluation of coke particle sizes. Karabasov et al. ${ }^{4)}$ reported that the combustion rate of 1-2 mm coke particles was the highest. Mikhalevich et al, ${ }^{5)}$ reported that the combustion rate was the highest and the maximum temperature in the 
sintering bed was raised when 1.6-2.5 mm coke particles were used. Loo $^{6)}$ reported that the permeability in the sintering bed was the best when 1-2 mm coke particles were used but the $\mathrm{CO}_{2} /\left(\mathrm{CO}+\mathrm{CO}_{2}\right)\left[Y_{\mathrm{CO}_{2}}\right]$ content of the exhaust gas and productivity were decreased when coke particles under $0.25 \mathrm{~mm}$ were used. Based on the results of analysis of quasi-particles, Teo et al. ${ }^{7)}$ pointed out that fine coke breeze under $0.25 \mathrm{~mm}$ penetrated into the fine particles adhering to the quasi-particles but $0.25-1 \mathrm{~mm}$ particles adhered to the surface of quasiparticles, while particles over $1 \mathrm{~mm}$ tended to exist alone. The technologies in practical use for coke breeze granulation include the method by disc pelletizer. ${ }^{8)}$

\section{Importance of Coke Particle Size in Temperature Distribution in the Sintering Bed}

\subsection{Mathematical Model Analysis of Temperature Distribution in the Sintering Bed}

In the actual sintering bed, various sizes of coke particles produced in the crushing process are used in a mixed manner. Here, the following mathematical model analysis $^{9,10)}$ is conducted, setting an ideal system, consisting of a single size of coke particles only, as the most fundamental system. In this system, the volume of draft air is assumed to be constant.

There are two papers on mathematical model of iron ore sintering including coke combustion. In Hamada's paper, ${ }^{11)}$ the temperature of coke particle was calculated independently from that of raw material. Therefore, very high value $(2273 \mathrm{~K})$ was obtained for coke particle temperature. For very high temperature range above $2000 \mathrm{~K}$, Hamada et al. used the coke reaction constant which can be applied under $1723 \mathrm{~K}$. In paper reported by Horio et al., ${ }^{12)}$ the decomposition of limestone and the melting of raw materials were neglected. These two reactions are essential phenomena in sintering process of iron ores, so Horio's simulation is considered not to be accurate for these discussions.

In author's mathematical model, the following reaction and rate constant are used.

$$
\begin{gathered}
\mathrm{C}+\mathrm{O}_{2} \rightarrow \mathrm{CO}_{2} \\
k_{c}=3.92 \times 10^{9} \cdot e^{-44000 / R \cdot T_{s}} \sqrt{T_{s}} \cdot C_{\mathrm{O}_{2}}
\end{gathered}
$$

where $R$ is gas constant. In addition, the limestone reaction and melting-solidification phenomena were included in this mathematical model. Therefore, the model can obtain more actual results than above two papers.

\subsubsection{Moisture Condensation and Drying Region}

Enthalpy balance, viewed from gas and solid:

$$
\begin{aligned}
& G\left\{C_{g}+C_{h} \cdot W_{g}\right\} \cdot\left(\delta T_{g} / \delta X\right)+S_{e} \cdot h_{c}\left(T_{g}-T_{s}\right) \\
& -R_{w}^{*} \cdot C_{h} \cdot T_{g}=0 \\
& (1-\varepsilon) \rho_{s}\left(C_{s}+C_{w} \cdot W_{s}\right) \cdot\left(\delta T_{s} / \delta \tau\right) \\
& =S_{e} \cdot h_{c}\left(T_{g}-T_{s}\right)+R_{w}^{*}\left(\lambda_{w}-C_{w} \cdot T_{s}\right)
\end{aligned}
$$

Material balance for moisture, viewed from gas and solid:

$$
-G \cdot\left(\delta W_{g} / \delta X\right)=R_{w}^{*}
$$

$$
(1-\varepsilon) \rho_{s} \cdot W_{s} \cdot\left(\delta W_{s} / \delta \tau\right)=R_{w}^{*}
$$

Velocity equations for constant-rate drying and decreasing-rate drying processes:

$$
\begin{aligned}
& R_{w}^{*}=S_{e} \cdot h_{c}\left(T_{g}-T_{s}\right) / \lambda_{\mathrm{w}} \\
& R_{w}^{*}=S_{e} \cdot h_{c}\left(T_{g}-T_{s}\right) / \lambda_{\mathrm{w}} \times\left(W_{s}-W_{e}\right) /\left(W_{c}-W_{e}\right)
\end{aligned}
$$

Velocity equation for moisture condensation process:

$$
R_{w}^{*}=G \cdot\left(\delta W_{g} / \delta T_{g}\right) \cdot\left(\delta T_{g} / \delta X\right)
$$

3.1.2. Heating Process, Reaction Process, and Melting and Solidification Process

Enthalpy balance, viewed from gas and solid:

$$
\begin{aligned}
& -\delta\left(G \cdot C_{g} \cdot T_{g}\right) / \delta X=S_{e} \cdot h_{c}\left(T_{g}-T_{s}\right) \\
& (1-\varepsilon) \rho_{s} \cdot \delta\left(C_{s} T_{s}+H\right) / \delta \tau \\
& \quad=S_{e} \cdot h_{c}\left(T_{g}-T_{s}\right)+\Delta H_{c} \cdot R_{c}^{*}-\Delta H_{e} \cdot R_{e}^{*}
\end{aligned}
$$

Equation of continuity, viewed from gas:

$$
-\delta G / \delta X+M_{c} \cdot R_{c}^{*} / \rho_{c}+M_{e} \cdot R_{e}^{*} / \rho_{e}=\varepsilon \cdot\left(\delta \rho_{g} / \delta \tau\right)
$$

Balance for oxygen and carbon dioxide in gas

$$
\begin{aligned}
& -\delta\left(G \cdot C_{\mathrm{O}_{2}} / \rho_{g}\right) / \delta X-R_{c}^{*} / \rho_{\mathrm{c}}=\varepsilon \cdot\left(\delta C_{\mathrm{O}_{2}} / \delta \tau\right) \\
& -\delta\left(G \cdot C_{\mathrm{CO}_{2}} / \rho_{g}\right) / \delta X+R_{c}^{*}+R_{e}^{*}=\varepsilon \cdot\left(\delta C_{\mathrm{CO}_{2}} / \delta \tau\right)
\end{aligned}
$$

Material balance for coke and limestone particles:

$$
\begin{aligned}
& \rho_{c} \cdot 4 \pi \cdot r_{c}^{2} \cdot\left(\delta r_{c} / \delta \tau\right)=-M_{c} \cdot R_{c}^{*} \\
& \rho_{e} \cdot 4 \pi \cdot r_{e}^{2} \cdot\left(\delta r_{e} / \delta \tau\right)=-M_{e} \cdot R_{e}^{*}
\end{aligned}
$$

Reaction rate per coke and limestone particle:

$$
\begin{aligned}
& r_{c}^{*}=4 \pi \cdot r_{c}^{2} \cdot k_{c} \cdot C_{\mathrm{O}_{2}} \ldots \ldots \ldots \ldots \ldots \\
& r_{e}^{*}=4 \pi \cdot r_{e}^{2} \cdot k_{e} \cdot\left(C_{\mathrm{CO}_{2}}^{*}-C_{\mathrm{CO}_{2}}\right)
\end{aligned}
$$

Iron ore melting and solidification process:

The melting and solidification phenomena were presented as follows:

$$
-\frac{\delta H}{\delta \tau}=-\frac{\delta H}{\delta T_{s}} \cdot \frac{\delta T_{s}}{\delta \tau}
$$

Here, $\delta H / \delta T_{s}$ shows the change of the latent heat of solids, and it is assumed to be constant during melting. Therefore,

$$
\int_{T_{m 1}}^{T_{m 2}} \delta H / \delta T_{s} \cdot d T_{s}=C\left(T_{m 2}-T_{m 1}\right)
$$

where $C$ is integral constant.

The sum of $\delta H / \delta T_{s}$ should be equal to $H_{m 0}$, so

$$
C=H_{m 0} /\left(T_{m 2}-T_{m 1}\right)
$$

Finally, the equation is given by:

$$
-\delta H / \delta \tau=H_{m 0} \cdot\left(\delta T_{s} / \delta \tau\right) /\left(T_{m 1}-T_{m 2}\right)
$$

\subsection{Effect on Temperature Distribution Characteristics in the Sintering Bed}

To compare the characteristics of temperature distribution behavior in the sintering bed, the behaviors of the following items were studied to predict the effect of coke particle size on changes in temperature dis- 


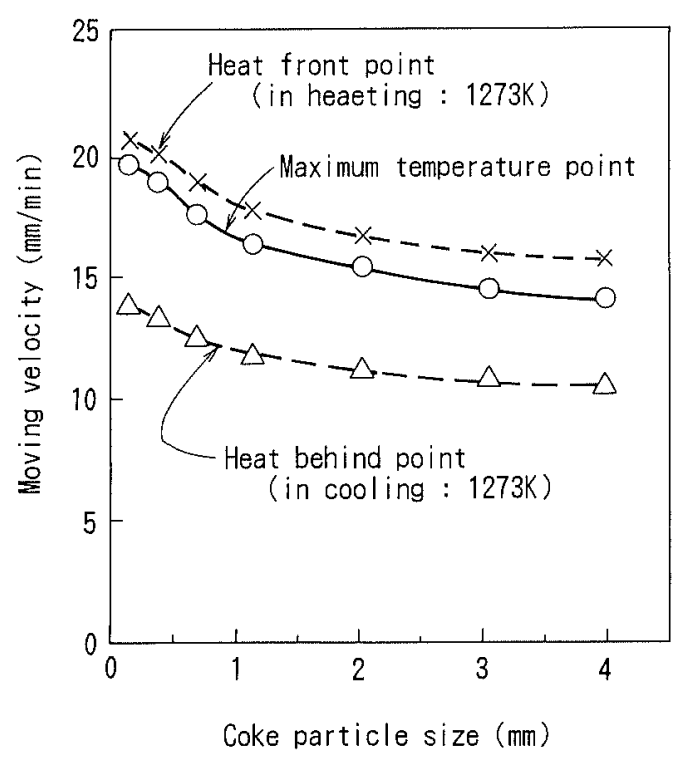

Fig. 1. Moving velocity of heat wave at a level of $120 \mathrm{~mm}$ from the top of sintering bed.

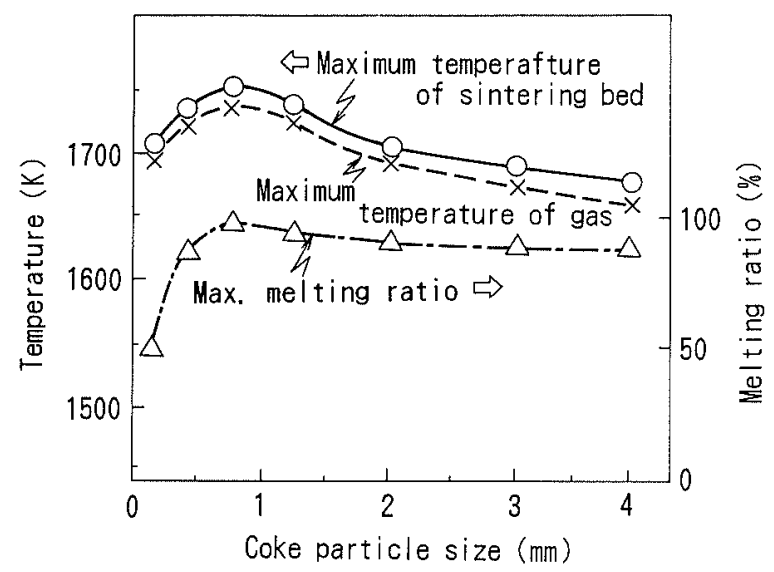

Fig. 2. Maximum temperature of heat wave at a level of $120 \mathrm{~mm}$ from the top of sintering bed.

tribution in the sintering bed by using various sizes of coke particles.

(1) Moving velocity of the maximum temperature point in the temperature distribution in the sintering bed

(2) Moving velocity of the heat front point $(1273 \mathrm{~K}$ in our study) in the heating process

(3) Moving velocity of the heat behind point ( $1273 \mathrm{~K}$ in our study) in the cooling process

The results of theoretical calculation are shown in Fig. 1. It will be noted that the combustion speed per unit volume $\left(\mathrm{kg} /\left(\mathrm{min} \cdot \mathrm{m}^{3}\right)\right)$ becomes faster and the moving velocity increases with decreasing coke particle size. Meanwhile, the time required until the completion of reaction increases with increasing coke particle size, and therefore the reaction is obstructed as it overlaps the raw mix melting process. As a result, temperature rise in the latter half of temperature distribution is suppressed. It is clear from Fig. 2 that there exists such a coke particle size at which the max. temperature in the sintering bed becomes the highest. Moreover, if the coke particle size is decreased from the above particle size, heating is accelerated and the heat wave is spread toward the thickness direction of the bed (i.e., the distance between the heat front point and the heat behind point is increased as shown in Fig. 1), resulting in dropping of the max. temperature point and decreases in the melting ratio of the raw mix for sintering. Therefore, a coke particle size, which provides maximum value for both the max. temperature in the sintering bed and the melting ratio of the raw mix, is estimated to be in the range from 0.5 to $1.5 \mathrm{~mm}$.

\section{Results of Granulation Test by Centrifugal Rolling Type Pelletizer}

From the mathematical model analysis of temperature distribution in the sintering bed, it was found that coke particles of $0.5-1.5 \mathrm{~mm}$ are optimum from the standpoints of max. temperature in the sintering bed and the melting ratio of the raw mix. Based on this finding, a study was made on coke breeze granulation by a centrifugal rolling type pelletizer to increase the ratio of particles above $0.5 \mathrm{~mm}$ by granulating fine coke particles under $0.5 \mathrm{~mm}$.

\subsection{Adoption of Centrifugal Rolling Type Pelletizer}

The most widely used pelletizers for sintering are the drum mixer and disc pelletizer, while the mixer with high-speed agitator is finding limited application. ${ }^{13}$ ) However, the weak point of drum mixer and disc pelletizer lies in the control of coarse particles as described previously.

For our test, we adopted a centrifugal rolling type pelletizer (Marumerizer (trade name)) ${ }^{2)}$ - Froude number is more than $10^{2}$ times those for the drum mixer and disc pelletizer, the diameter being smaller than $1 \mathrm{~m}(50 \mathrm{ll}$ batch) which is widely used in the medical supplies and food industries. The centrifugal rolling type pelletizer consists of a rotary disc and a fixed sidewall. As the swirling motion (the rotation of particles and the revolution of the bed) is repeated over the entire outer periphery, it produces solid granulated coke particles with a narrow particle size distribution.

\subsection{Results of Granulation Test}

In the pot test, a $600 \mathrm{~mm} \phi$ centrifugal rolling type pelletizer shown in Fig. 3 was employed. The rotating speed of this pelletizer was set to $300 \mathrm{rpm}$ so that a peripheral velocity of $9.4 \mathrm{~m} / \mathrm{s}$ was obtained (the optimum velocity was determined by conducting preliminary tests).

The optimum values for the treated quantity of coke, granulating time, amount of water added, amount of binder (quick lime), etc. were determined by changing them in various ways. Granulation was carried out with intermittent and continuous discharge. The particle size distribution in the granulated breeze was examined by screening the granulated particles through a vibrating screen for $5 \mathrm{~min}$ after drying them up $1 \%$ moisture.

Figure 4 shows the results of the granulation test by the centrifugal rolling type pelletizer $(600 \mathrm{~mm} \phi$ in inside diameter, $300 \mathrm{rpm} \times 2 \mathrm{~min}$ ) using fine coke breeze (under $0.5 \mathrm{~mm}$ ) in comparison with those of the test conducted using a mixer with high-speed agitator $(700 \mathrm{~mm}$ in inside 


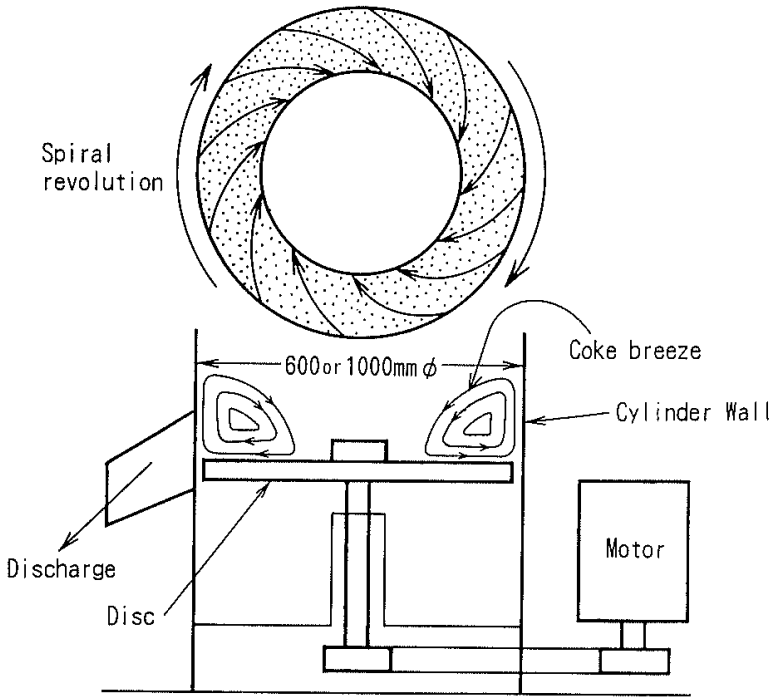

Fig. 3. Schematic diagram of centrifugal rolling type pelletizer.

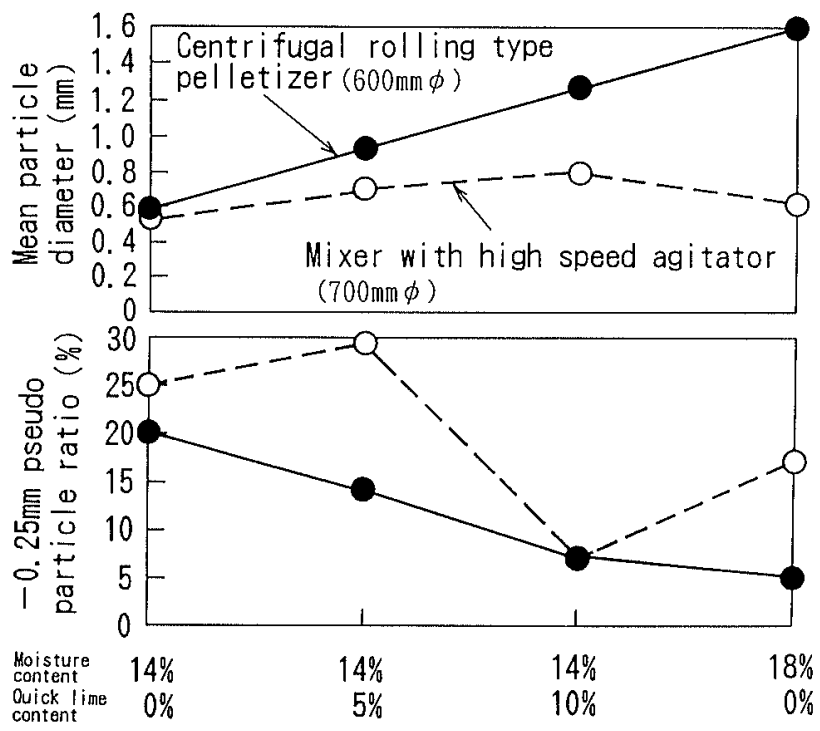

Fig. 4. Results of granulation test by centrifugal rolling type pelletizer in comparison with those by mixer with high-speed agitator.

diameter, $28 \mathrm{rpm} \times 2 \mathrm{~min}$, agitator: $500 \mathrm{rpm}$ ). When the centrifugal rolling type pelletizer was used, the ratio of fine particles in the granulated coke breeze was lower and the size of the particles formed by granulating fine particles with each other was larger. The addition of quick lime contributed to the improvement of granularity.

In case of the centrifugal rolling type pelletizer, the coke breeze was well granulated at a high moisture level of $18 \mathrm{mass} \%$. On the other hand, the quasi-particles of coke breeze granulated by the mixer with high-speed agitator at that moisture level collapsed.

\section{Results of Tests and Discussion}

\subsection{Sintering Pot Test Method and Results of Test}

\subsubsection{Sintering Pot Test Apparatus}

The conventional type sintering pot test apparatus (300 $\mathrm{mm}$ in inside diameter, $365 \mathrm{~mm}$ in height, $10.8 \mathrm{kPa}$ in negative pressure, sand seal method ${ }^{14)}$ which can suppress the excessive air flow velocity near the wall) was used. The quantity of the raw mix charged was about $35 \mathrm{~kg}$ and the thickness of the hearth layer was $20 \mathrm{~mm}$. The raw mix (about $2.2 \mathrm{~mm}$ in mean particle size) was granulated (moisture after granulation: about $6.3 \%$ ) in a concrete mixer $(580 \mathrm{~mm}$ in inside diameter, $30 \mathrm{rpm} \times$ $3 \mathrm{~min}$ ). Coke breeze (C: 84 mass\%, N: 1.2 mass\%) was granulated by the centrifugal rolling type pelletizer described in Chapter 4. Changes in $\mathrm{CO}_{2}, \mathrm{CO}, \mathrm{O}_{2}$ and nitrogen oxide in the exhaust gas were measured mainly by an infrared analyzer. The nitrogen oxide being referred to herein is NO.

After dropping the sintered product five times from a height of $2 \mathrm{~m}$, the quantity of particles above $5 \mathrm{~mm}$ was taken as the quantity of product. The product yield was calculated by dividing the quantity of product by the value obtained by subtracting the quantity of hearth layer from the total quantity sintered. The tumble index was determined by calculating the percentage of sinter particles larger than $10 \mathrm{~mm}$ after rotating the sample $(50-25 \mathrm{~mm}: 11.5 \mathrm{~kg}, 25-10 \mathrm{~mm}: 11.5 \mathrm{~kg})$ for 200 turns at a speed of $24 \mathrm{rpm}$ by using a tumble test apparatus specified in JIS M 8712-1982 which is similar to ASTM E 279 (drum diameter: $914 \mathrm{~mm}$ ). The RDI was measured by the method of the Ironmaking Committee of ISIJ.

\subsubsection{Results of Sintering Pot Test}

(1) Granulation of fine coke breeze (the particles under $1 \mathrm{~mm}$ )

The particles under $1 \mathrm{~mm}$ only were granulated. Sintering pot test was conducted using two types of coke breeze: coke breeze consisting of particles under $1 \mathrm{~mm}$ only, and coke breeze, consisting of $40 \%$ of $3-1 \mathrm{~mm}$ particles and $60 \%$ of particles under $1 \mathrm{~mm}$. The mixing ratio of coke breeze was 3.7 mass $\%$. The granulating condition by the centrifugal rolling type pelletizer $(600 \mathrm{~mm} \phi)$ was as follows: batch type granulation at a rotating speed of $300 \mathrm{rpm}$, granulating time being $120 \mathrm{~s}$. Granulation was conducted in two different ways, i.e., granulation with the addition of water and granulation with simultaneous addition of water and quick lime (the ratio of quick lime in the raw mix was held constant).

Figure 5 shows a micrograph of granulated coke breeze. It will be noted that granulated particles are adhering to quick lime even after complete drying.

Figure 6 shows an example of combustion behavior in the sintering process where coke breeze (under $1 \mathrm{~mm}$ ) only was used.

The carbon mass in exhaust gas was calculated from $\mathrm{CO}$ and $\mathrm{CO}_{2}$ contents of exhaust gas. In the sintering process, the coke breeze begins to burn at a temperature of about $973 \mathrm{~K}$. And at this temperature, limestone fines also start to decompose. Moreover, the carbon mass from coke breeze is about 2.5 times than that from limestone. Therefore, the mass of gaseous carbon generated during sintering process was considered to be proportional to the combustion rate $(\mathrm{kg} / \mathrm{min})$ of coke breeze.

Figure 7 shows the results of sintering pot test in which granulated coke breeze was used for $60 \%$ of the total quantity of coke breeze. When granulated coke breeze 


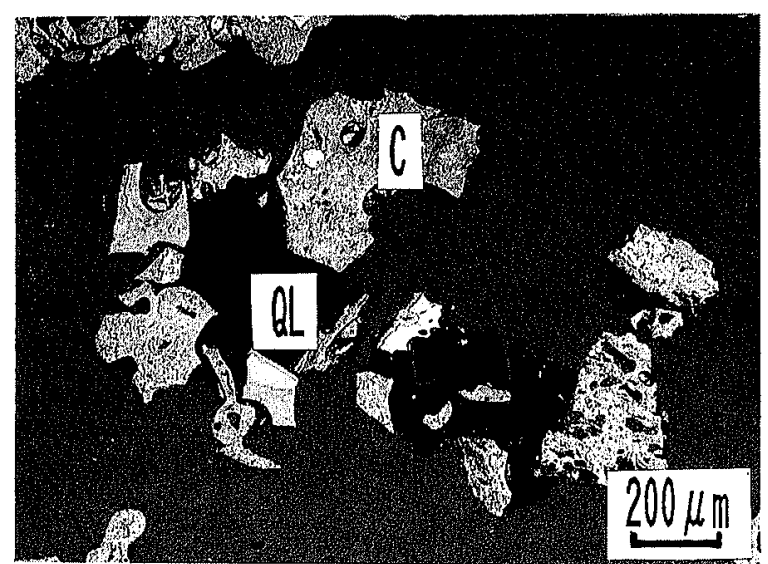

\section{C:Coke breeze QL:Quick Iime}

Fig. 5. Micrograph of coke breeze granulated by centrifugal rolling type pelletizer.

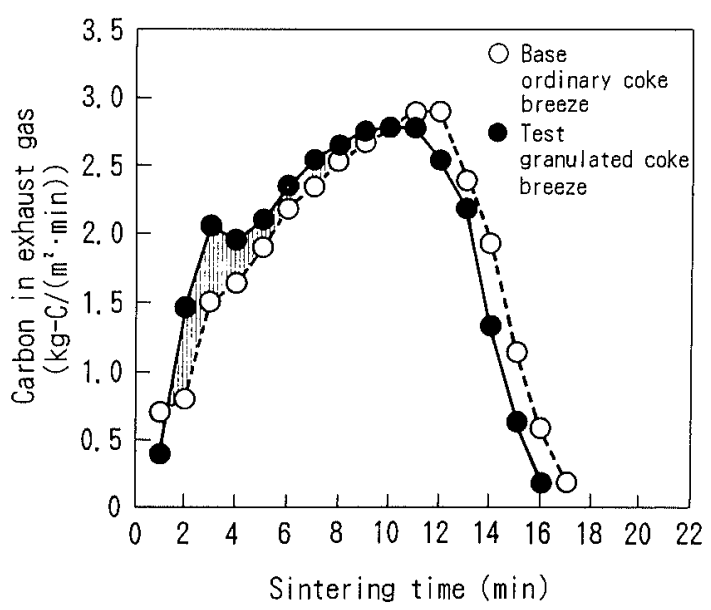

Fig. 6. Changes in carbon content of exhaust gas in the sintering pot test.

was used, the coke combustion rate was increased in the first-half period of sintering. The draft air rate was increased by about $15 \%$ throughout sintering, while carbon mass in exhaust gas was increased by about $25 \%$ on an average from the beginning to 4 min of sintering. It was, therefore, considered that the improvement of granulated coke combustion rate $(\mathrm{kg} / \mathrm{min})$ was larger than that of the draft air rate. It was clarified that granulated coke particles became easy to burn. In the pot test, such effects as the reduction in sintering time, the improvement of pot yield, the improvement of RDI, and the reduction in unit NO consumption were observed. The pot yield was calculated by dividing the quantity of product by the value obtained by the dry charged sinter mix excluding coke breeze. It was also confirmed that unit NO consumption was further reduced by the addition of quick lime.

(2) Granulation of coke breeze (the particles under $5 \mathrm{~mm}$ )

The particles under $5 \mathrm{~mm}$ were granulated. In consideration of the fuel mixing ratio in the plant test, the fuel mixing ratio was determined at 2.8 mass $\%$ of granulated coke breeze and 1.2 mass $\%$ of anthracite.
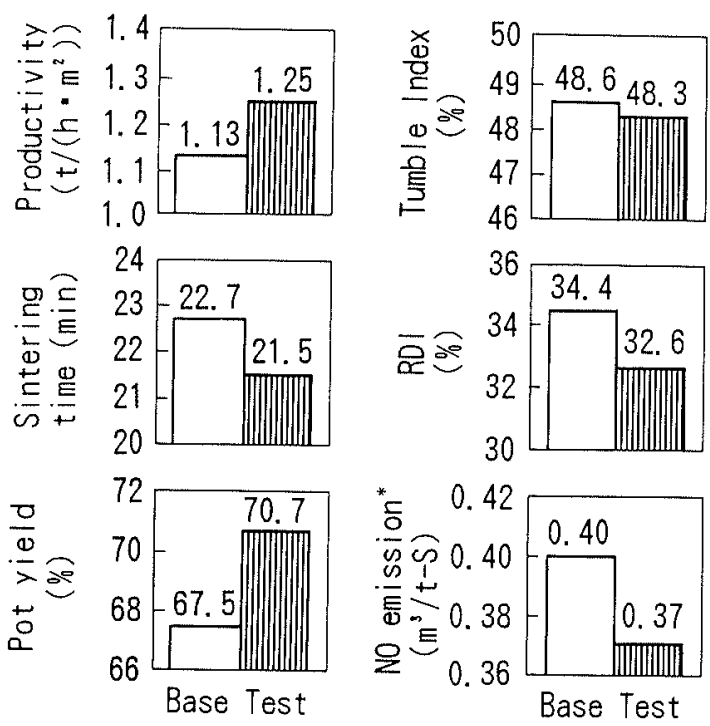

Base: ordinary coke breeze

Test: granulated coke breeze * $m^{3}$ : at STP

Fig. 7. Results of sintering pot test using ordinary coke breeze in comparison with those of test using granulated coke breeze (Coke breeze size: under $1 \mathrm{~mm}$ before granulation).

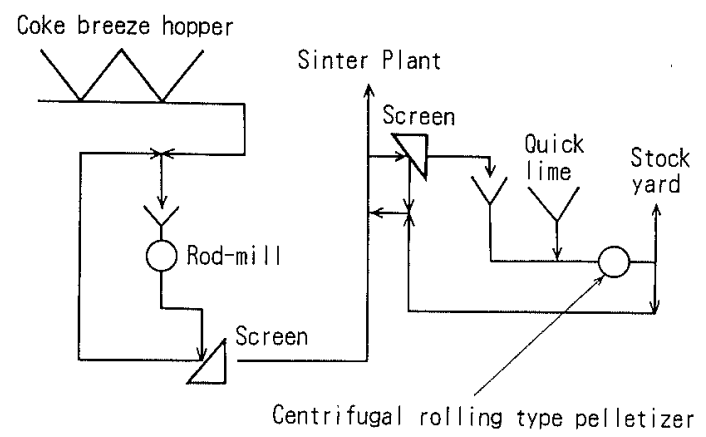

Fig. 8. Test apparatus at Nagoya No. 2 Sintering Plant.

Granulation by the centrifugal rolling type pelletizer was accomplished with the addition of water at a rotating speed of $200 \mathrm{rpm}$ for about $10 \mathrm{sec}$. The coke breeze particles under $5 \mathrm{~mm}$ were granulated with continuous discharge. In the granulated coke breeze, the ratio of fine particles (under $1 \mathrm{~mm}$ ) decreased by about 10 mass $\%$ (from 45 to $35 \%$ ) but that of coarse particles (above $5 \mathrm{~mm}$ ) was little increased.

As a result of the pot test which was conducted using ordinary or granulated coke breeze, the following improvements of granulated coke breeze were observed: (1) productivity by $6 \%$, (2) product yield by $1.9 \%$, (3) $Y_{\mathrm{CO}_{2}}$ by $1.6 \%$, and (4) unit NO consumption by $10 \%$.

\subsection{Plant Test Method and Results of Test}

\subsubsection{Plant Test Method}

A $1000 \mathrm{~mm} \phi$ centrifugal rolling type pelletizer was connected to the final conveyor of the coke breeze crushing plant for the Nagoya No. 2 sintering machine $\left(196 \mathrm{~m}^{2}\right)$ in commercial operation. The flow at this pilot plant is shown in Fig. 8. After taking out part of coke breeze and removing particles larger than $5 \mathrm{~mm}$, the coke 
particles under $5 \mathrm{~mm}$ were granulated with continuous discharge ( $5 \mathrm{t} / \mathrm{h}, 200 \mathrm{rpm}$, granulating time: about $10 \mathrm{sec})$. The granulated coke breeze was returned to the coke breeze transport conveyor and mixed with ordinary coke breeze so that the ratio of granulated coke breeze in the fuel (coke breeze + anthracite) became about $30 \%$. Because of limitations on weighing equipment, the granulation of coke breeze with anthracite was not conducted. In the test in which the granulated coke breeze was used in a ratio of about $70 \%$ of the fuel; the granulated coke breeze was stored in the yard for several weeks and then carried in from the coke breeze receiving hopper.

\subsubsection{Results of Plant Test}

Granulation test with the addition of "water + quick lime" was conducted on condition that the granulated coke breeze is used in about $30 \%$ of the fuel. The ratio of quick lime in the raw mix was held constant. In the granulated coke breeze, the ratio of coke particles under $0.5 \mathrm{~mm}$ was decreased by about 15 mass \% (from 35 to $20 \%$ ) but that of particles above $5 \mathrm{~mm}$ remained unchanged. According to the results of the plant test which was conducted using granulated coke breeze three times, (1) $\mathrm{NO}_{x}\left(\mathrm{O}_{2}: 15 \mathrm{vol} \%\right)$ was decreased by $6-20 \mathrm{ppm}$, (2) the product yield was increased by $1.5 \%$, and (3) $Y_{\mathrm{CO}_{2}}$ was increased by $1 \%$ in comparison with using ordinary coke breeze. As shown in Table 1, the GI index ${ }^{15)}$ representing the degree of granulation of raw mix for sintering into quasi-particles was improved by 15-30\% throughout the sintering bed from the top to the hearth.

Though the coke breeze mixing ratio was several mass $\%$, this ratio corresponds to over $10 \mathrm{vol} \%$ in terms of volume ratio as the bulk density of coke breeze is about $1 / 5$ of that of iron ore. It is, therefore, estimated from the results described above that coke breeze granulation has a great effect on the granulation of raw mix for sintering into quasi-particles.

In the test using the fuel, containing about $70 \%$ of granulated coke breeze, the whole quantity of ordinary coke breeze was substituted by the granulated coke which had been stored in the yard. The results of this test are shown in Table 2 . When the base operation using ordinary coke breeze was changed over to the test operation using granulated coke breeze, $\mathrm{NO}_{x}\left(\mathrm{O}_{2}: 15\right.$ vol $\%$ ) was immediately decreased by more than $10 \mathrm{ppm}$. At the same time, $\mathrm{FeO}$ in the sinter was slightly decreased. Though the tumble index and RDI did not show noticeable changes, JIS-RI was improved by about $2 \%$. The product yield was held nearly constant. It is estimated that the improvement of permeability of the sintering bed contributes to the reduction in $\mathrm{NO}_{x}$ emissions, and the reduction in the time during which the highest temperature in the sintering bed can be maintained, ${ }^{15)}$ thus resulting in the reduction of $\mathrm{FeO}$. The improvement of JIS-RI is considered to be attributable largely to the effect of reduction in $\mathrm{FeO}$.

Figure 9 shows the microstructures of the quasiparticles of the raw mix in the base operation using ordinary coke breeze and in the test operation using granulated coke breeze. The quasi-particles of the raw
Table 1. Improvement of quasi-particle granulation in the sintering bed by the new method.

\begin{tabular}{|c|c|c|c|}
\hline \multirow{2}{*}{ Sampling position } & \multicolumn{2}{|c|}{ GI $(\%)$} & \multirow{2}{*}{$\begin{array}{c}\text { Improvement } \\
\text { in GI } \\
(\%)\end{array}$} \\
\hline & $\begin{array}{l}\text { Ordinary } \\
\text { method }\end{array}$ & $\begin{array}{c}\text { New } \\
\text { method }\end{array}$ & \\
\hline $0-50 \mathrm{~mm}$ from bed top & $3 I$ & 54 & +23 \\
\hline $50-100 \mathrm{~mm}$ & 59 & 92 & +33 \\
\hline $100-150 \mathrm{~mm}$ & 76 & 98 & +22 \\
\hline $150-200 \mathrm{~mm}$ & 79 & 94 & +15 \\
\hline $200-300 \mathrm{~mm}$ & 80 & 99 & +19 \\
\hline $200-400 \mathrm{~mm}$ & 79 & 100 & +21 \\
\hline
\end{tabular}

Granulation index $(\mathrm{GI})=\left\{\left(A_{1}-B_{1}\right) / A_{1}+\left(A_{2}-B_{2}\right) / A_{2}\right\} \times 100$. True particles: $A_{1}(0.5-0.25 \mathrm{~mm}$ fines mass $\%), A_{2}$ (under $0.25 \mathrm{~mm}$ fines mass \%). Quasi-particles: $B_{1}\left(0.5-0.25 \mathrm{~mm}\right.$ fines mass\%), $B_{2}$ (under $0.25 \mathrm{~mm}$ fines mass $\%$ ). Bed height: $500 \mathrm{~mm}$ including hearth layer.

Table 2. Sintering performance at Nagoya No. 2 Sintering Plant.

\begin{tabular}{lcc}
\hline & Base & Test \\
\hline Period $(\mathrm{h})$ & 24 & 10 \\
Productivity $\left(\mathrm{t} /\left(\mathrm{h} \cdot \mathrm{m}^{2}\right)\right)$ & 1.43 & 1.45 \\
Yield (mass\%) & 79.3 & 78.6 \\
Coke content in raw mix (mass\%) & 2.86 & 2.86 \\
$\mathrm{FeO}$ in sinter (mass\%) & 6.29 & 5.76 \\
$\mathrm{SiO}_{2}$ in sinter (mass\%) & 5.45 & 5.51 \\
$\mathrm{Tumble}$ index $(\%)$ & 71.9 & 71.6 \\
$\mathrm{RDI}(\%)$ & 29.7 & 30.4 \\
$\mathrm{JIS}-\mathrm{RI}(\%)$ & 66.1 & 67.7 \\
$\mathrm{NO}_{x}\left(\mathrm{O}_{2}: 15\right.$ vol\%)* $(\mathrm{ppm})$ & 170 & 158 \\
\hline
\end{tabular}

Base: ordinary coke breeze, Test: granulated coke breeze.

${ }^{*} \mathrm{NO}_{x}\left(\mathrm{O}_{2}: 15 \mathrm{vol} \%\right)$ : value corrected at $15 \mathrm{vol} \%$ of oxygen concentration of exhaust gas.

mix were taken from the exit of the drum feeder of the surge hopper for sintering machine. In the base operation, iron ore adhered to the coke breeze which became the nucleus of quasi-particle was observed, but the adhesion of fine coke particles to it was not observed. In the test operation using granulated coke breeze, fine coke particles adhered even to the interior of the coke breeze which became the nuclei of quasi-particles. The fine coke breeze particles adhering to each other also became the nuclei of quasi-particles, though the quantity of such particles was small. This photograph shows that the granulated coke breeze by using quick lime as a binder has a strength high enough to withstand disintegration at the time of rolling together with the raw mix for sintering in the drum mixer.

The microstructure of the sinter in the base operation is characterized in that (1) the area of the microstructure in which magnetite, columnar calcium ferrite, and slag coexist is large and (2) the quantity of hematite existing in the vicinity of pores is small. In the test operation using granulated coke breeze, (1) the area of the microstructure in which magnetite, fine calcium ferrite, and slag (though small in volume) coexist is large and (2) the quantity of hematite existing in the vicinity of pores is noticeable. It is estimated that the improvement of JIS-RI by about $2 \%$ is attributable to the refinement of calcium ferrite and the increase in hematite. ${ }^{16)}$ 


\subsection{Comparison of Froude Numbers Used in the Opera- tion of Granulating Machines}

Table 3 shows the representative Froude numbers ${ }^{17)}$ (calculated by Eq. (18)) used in the operation of the drum mixer, disc pelletizer, mixer with high-speed agitator, and centrifugal rolling type pelletizer.

$$
F r=D(N / 60)^{2} / g
$$

where, $F r$ : representative Froude number $(-)$

$D:$ diameter of rotor $(\mathrm{m})$

$N$ : speed of rotation (r.p.m.)

$g:$ gravitational acceleration $\left(=9.8 \mathrm{~m} \cdot \mathrm{s}^{-2}\right)$.

The Froude number used in the operation of the centrifugal rolling type pelletizer is more than $10^{2}$ times those for the drum mixer and disc pelletizer. It is estimated that the centrifugal rolling type pelletizer granulates coke breeze under the centrifugal force which is
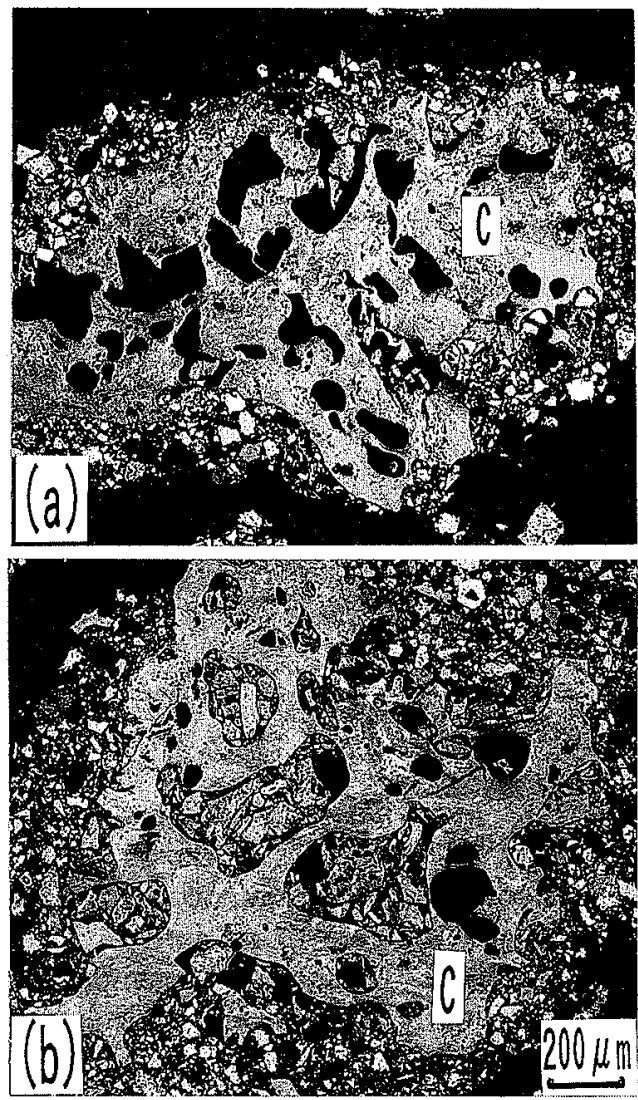

\section{C:Coke breeze}

(a) The nucleus of quasi-particle is a coarse coke particle (Base)

(b) The nucleus particle is an agglomerate of coarse and fine coke breeze (Test)

Fig. 9. Microstructures of quasi-particles of raw mix. several times as large as the gravitational force. It is, therefore, considered that coarsening of coke particles can be prevented due to the "rubbing" effect by the pelletizer even if fine particles adhere to coarse particles. With the mixer with high-speed agitator, the Froude number of the agitating blade is high but that of the rotary pan is only about 5 times those for the drum mixer and disc pelletizer.

The centrifugal rolling type pelletizer can make dense quasi-particles by the centrifugal force of high-speed rotating disc, ${ }^{3)}$ while in case of the mixer with high-speed agitator the quasi-particle densifying effect of agitator is smaller than that of the centrifugal rolling type pelletizer, though preventing quasi-particles from becoming excessively coarse.

\subsection{Effect of Coke Breeze Granulation on the Granula- tion of Raw Mix for Sintering into Quasi-particles}

It is said that granulation of raw mix for sintering into quasi-particles deteriorates if coke breeze adheres to the raw mix but is improved if coke breeze becomes the nucleus of quasi-particles of the raw mix. ${ }^{18)}$ It will be quite possible that the granulation of raw mix for sintering may deteriorate if coke breeze with different specific gravity is mixed with adhering fine particles. It is, therefore, considered that the granulation of the raw mix for sintering into quasi-particles will be improved as shown in Table 1 if the quantity of fine coke particles which penetrate into the fine particles adhering to quasi-particles can be reduced by causing fine coke breeze to adhere to the interior of coarse coke particles (Fig. 9).

\subsection{Effect of Granulated Coke on Coke Combustion Rate and Suppression of $\mathrm{NO}_{x}$ Emissions}

One of the reasons why the coke combustion rate increases due to coke breeze granulation is the improvement of granulation of the raw mix for sintering into quasi-particles. It is estimated that the coke combustion rate is increased due to the increase in oxygen concentration on the coke surface with the improvement of permeability of the sintering bed.

If the coke combustion rate is increased, the coke surface temperature rises and oxygen consumption increases. Under this condition, an atmosphere with high $\mathrm{CO} / \mathrm{O}_{2}$ is formed on the coke surface, suppressing $\mathrm{NO}_{x}$ emissions. ${ }^{19)}$ In addition, Hida et $a .^{20)}$ reported that aggregate coke decreased the $\mathrm{NO}_{x}$ formation. The structure of aggregate coke is ${ }^{-}$similar to that of the agglomerate of coarse and fine coke breeze shown in Fig. 9. Therefore, it is estimated that the effect of pore structure of granulated coke breeze also suppresses $\mathrm{NO}_{x}$ emissions.

In the quasi-particles shown in Fig. 9, iron ore is

Table 3. Representative Froude numbers used in the operation of granulating machines.

\begin{tabular}{llr} 
& \multicolumn{1}{c}{ Drum, Disc } & Agitator \\
\hline Drum mixer & $6 \times(10 / 60)^{2} / 9.8=1.7 \times 10^{-2}$ & - \\
Disc pelletizer & $6 \times(20 / 60)^{2} / 9.8=3.4 \times 10^{-2}$ & - \\
Mixer with high speed agitator & $3 \times(40 / 60)^{2} / 9.8=13.6 \times 10^{-2}$ & $1 \times(500 / 60)^{2} / 9.8=7.1$ \\
Centrifugal rolling type pelletizer & $2 \times(200 / 60)^{2} / 9.8=2.3$ & - \\
\hline
\end{tabular}


adhering to the granulated coke. These particles resemble the quasi-particles which have the effect of removing $\mathrm{NO}_{x}$ (adhesion of a material of $\mathrm{CaO}-\mathrm{Fe}_{2} \mathrm{O}_{3}$ system to nucleus coke particles) as proposed by Wu et al. ${ }^{21)}$ It is also supposed that iron oxide acted as a catalyst at the time of coke combustion, suppressing $\mathrm{NO}_{x}$ emissions. ${ }^{21)}$ However, our study could not clarify this point. The reason why $\mathrm{NO}_{x}$ emissions are suppressed by increasing the quantity of $\mathrm{CaO}$ added at the time of coke breeze granulation may be the effect of the improved degree of granulation on the reduction in the ratio of fine particles in the coke breeze.

\section{Conclusions}

To reduce the ratio of fine particles in the coke breeze to be used in the sintering process, tests were conducted using a centrifugal rolling type pelletizer which is operated at a Froude number that is more than $10^{2}$ times that for the drum mixer. Then, the effects of granulated coke breeze on the sintering operation, the granulation of raw mix for sintering into quasi-particles, sinter quality, etc. were studied through mathematical model analysis, pot test and plant test. As a result, the following findings were obtained.

(1) Based on the analysis of the max. temperature in the sintering bed and the melting ratio of raw mix for sintering under the constant volume of draft air by mathematical models, it is estimated that the coke particle size, which provides maximum value for both the max. temperature in the sintering bed and the melting ratio of the raw mix, is $0.5-1.5 \mathrm{~mm}$.

(2) If coke breeze is granulated by a centrifugal rolling type pelletizer, it is possible to cause fine particles to adhere to each other or to the interior of coarse particles, while suppressing the adhesion of fine particles to the surface of coarse particles.

(3) The granulated coke breeze becomes the nuclei of quasi-particles, improving the granulation degree of the whole quantity of raw mix for sintering into quasiparticles. The coke breeze granulated by using quick lime as a binder has a strength high enough to withstand disintegration at the time of rolling together with the raw mix for sintering in the drum mixer in commercial operation.

(4) As the ratio of fine particles of coke decreases, the coke combustion rate increases and $\mathrm{NO}_{x}$ emissions are suppressed. The reducibility of sinter is also improved.

\section{Nomenclature}

$C_{\mathrm{CO}_{2}}, C_{\mathrm{CO}_{2}}^{*}, C_{\mathrm{O}_{2}}:$ carbon dioxide concentration, equilibrium carbon dioxide concentration, oxygen concentration $\left(\mathrm{mol} / \mathrm{m}^{3}\right.$ )

$C_{g}, C_{h}$ : specific heat of gas, specific heat of vapor $(\mathrm{J} /(\mathrm{kg} \cdot \mathrm{K}))$

$C_{s}, C_{w}$ : specific heat of solid, specific heat of water $(\mathrm{J} /(\mathrm{kg} \cdot \mathrm{K}))$

$G, h_{c}$ : mass velocity $\left(\mathrm{kg} /\left(\mathrm{m}^{2} \cdot \mathrm{min}\right)\right)$, coefficient of heat transmission $\left(\mathrm{J} /\left(\mathrm{m}^{2}\right.\right.$. $\min \cdot \mathrm{K})$ )

$H, H_{m 0}$ : melting variable, heat of melting of solid $(\mathrm{J} / \mathrm{kg})$

$\Delta H_{c}, \Delta H_{e}$ : heat of reaction of coke, heat of reaction of limestone $(\mathrm{J} / \mathrm{mol})$

$k_{c}, k_{e}$ : overall reaction rate constant of coke, overall reaction rate constant of limestone $(\mathrm{m} / \mathrm{min})$

$M_{c}, M_{e}$ : molecular weight of carbon, molecular weight of limestone $(\mathrm{kg} / \mathrm{mol})$

$R_{c}^{*}, R_{e}^{*}: \quad$ reaction rate of coke, reaction rate of limestone $\left(\mathrm{kg} /\left(\mathrm{min} \cdot \mathrm{m}^{3}\right)\right)$

$r_{c}, r_{e}:$ particle size of coke, particle size of limestone $(\mathrm{m})$

$S_{e}, T_{g}, T_{s}: \quad$ area of heat-transfer surface $\left(\mathrm{m}^{2} / \mathrm{m}^{3}\right)$, gas temperature $(\mathrm{K})$, bed temperature (K)

$T_{m 1}, T_{m 2}:$ melting start temperature, melting end temperature $(\mathrm{K})$

$W_{c}, W_{e}, W_{g}, W_{s}: \quad$ critical moisture content, equilibrium moisture content, gas humidity, moisture content of raw mix $(\mathrm{kg} / \mathrm{kg})$

$X, \varepsilon:$ distance from bed top $(\mathrm{m})$, void in the bed $(-)$

$\lambda_{w}, \tau$ : latent heat of vaporization $(\mathrm{J} / \mathrm{kg})$, elapsed time (min)

$\rho_{c}, \rho_{e}$ : density of coke, density of limestone $\left(\mathrm{kg} / \mathrm{m}^{3}\right)$

$\rho_{g}, \rho_{s}:$ density of gas, density of solid $\left(\mathrm{kg} / \mathrm{m}^{3}\right)$

\section{REFERENCES}

1) e.g. Handbook of Iron and Steel 3rd ed. vol. II, ed. by ISI.J, Maruzen, Tokyo, (1979), 115.

2) Handbook of Granulation, ed. by Association of Powder Process Industry \& Engineering, Oumu Co., Ltd., Tokyo, (1991), 166.

3) Koujou-sousa Serial (an enlarged edition of Granulation), ed. by Kagaku-kogyo-sha Co., Ltd., Tokyo, (1983), 114.

4) Yu. S. Karabasov, E. M. Voropaev and V. S. Valavin: IZv. V.U.Z Chernaya Metall., 5 (1976), 21.

5) A. G. Mikhalevich, V. G. Voskoboinikov, S. B. Ten, B. M Boranbaev and A. G. Rusakova: Stal , (1980), 357.

6) C. E. Loo: Ironmaking Steelmaking, 18 (1991), 33.

7) C. S. Teo, R. A. Mikka and C. E. Loo: ISIJ Int., 32 (1992), 1047

8) S. Aso, S. Tamura, K. Sato, H. Yoshida, T. Yoshimura and T. Nasuno: Seitetsu Kenkyu, (1990), No. 338, 15.

9) I. Muchi and J. Higuchi: Tetsu-to-Hagané, 56 (1970), 371

10) M. Wajima, Y. Hosotani, J. Shibata, H. Soma and K. Tasiro: Tetsu-to-Hagané, 68 (1982), 1719

11) T. Hamada, T. Koitabashi and K. Okabe: Tetsu-to-Hagané, 58 (1972), 1567

12) M. Horio, T. Ohtake and I. Muchi: Tetsu-to-Hagané, 60 (1974), 465.

13) K. Takada, M. Koura, T. Kawaguti and T. Yokoi: Tetsu-toHagané, 73 (1987), S65, S769.

14) H. Soma, M. Wajima, Y. Hosotani and K. Tasiro: Tetsu-toHagané, 68 (1982), 2200.

15) T. Furui, M. Kawazu, K. Sugawara, T. Fujiwara, M. Kagawa, A. Sawamura and S. Uno: Seitetsu Kenkyu, (1976), No. 288, 9.

16) N. Sakamoto, H. Fukuyo, Y. Iwata and T. Miyashita: Tetsu-toHagané, 70 (1984), 504.

17) S. Suzuki, K. Sato and M. Fujimoto: Tetsu-to-Hagané, 73 (1987), 1932.

18) K. Sato: Fusen, 28 (1981), 99.

19) Y. Hida, M. Sasaki and K. Itou: Tetsu-to-Hagané, 66 (1980), 1801.

20) Y. Hida, K. Ito and M. Sasaki: Tetsu-to-Hagané, 67 (1981), 1934.

21) S. Wu, T. Sugiyama, K. Morioka, E. Kasai and Y. Omori: Tetsu-to-Hagané, 80 (1994), 276 